\title{
La olvidada obra modernista de los Martínez Sierra: Granada. Guía emocional
}

\author{
LAURA LOZANO MARÍN \\ Universidad de Granada
}

Resumen: Este artículo pretende ofrecer un estudio de Granada. Guía emocional (1911), obra modernista del matrimonio Martínez Sierra. Este libro guarda un enorme interés ya que ha sido olvidado por la crítica literaria del siglo $X X$. Se trata de una obra que rompe el horizonte de expectativas del lector ya que no es una guía de viajes al uso sino que se constituye como un libro modernista escrito en prosa poética que describe la ciudad andaluza y plasma la sociedad española de principios de siglo $X X$ a través de la crítica social.

Palabras clave: Modernismo, Granada, Martínez Sierra, guía

\section{A forgotten modernist literary work:}

Granada. Guía emocional

Abstract: This article presents a study about Granada. Guía emocional (1991), modernist literary work created by the Martínez Sierra marriage. This book had been overlooked from the literary criticism of the twentieth century even when it holds a significant input to the Spanish literature. This literary work breaks the horizon of expectations from the readers, as it can't be regarded solely as a travel guide to use because it must be perceived as a modernist book written in poetic prose that describes the Andalusian city and captures the Spanish society of the early twentieth century through social criticism.

Keywords: modernism, Granada, Martínez Sierra, guide 


\section{INTRODUCCIÓN}

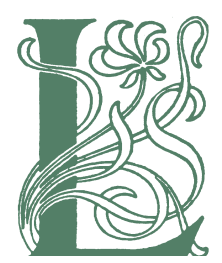

a obra de los Martínez Sierra, Granada. Guía emocional, ha pasado desapercibida tanto para los investigadores del siglo pasado como para los actuales. No existen estudios concretos dedicados completamente a esta obra a excepción de un artículo de Daniel Eisenberg (1995) en el que plantea la arriesgada teoría de que este libro habría sido una de las primeras guías para homosexuales de la época. Sin embargo, sí que se encuentran pequeñas referencias a la Guía emocional en obras más amplias. Lo que resulta más relevante de este aspecto es que las pocas alusiones y referencias que hay sobre esta obra no consiguen definirla en su plenitud. Granada. Guía emocional no es una guía de viajes al uso, sino que se trata de un libro modernista que contiene líricas descripciones de los paisajes y la sociedad de la ciudad que, además, posee una fuerte carga de crítica social y de defensa del papel de la mujer. Así, el objetivo de este artículo es el de estudiar estos temas y características que hacen de esta Guía emocional una obra diferente y peculiar con respecto a la tradicional guía de viajes.

Que este libro, publicado por primera vez en 1911, haya caído en el olvido podría deberse, por un lado, al título, ya que el lector puede pensar que se encuentra ante un libro o guía de viajes que simplemente se va a dedicar a describir la ciudad protagonista en términos modernistas. Si esta es la idea principal antes de sumergirse en la lectura de la obra, sin duda se producirá una ruptura en el horizonte de expectativas del lector. Por otro lado, está el hecho de que la obra aparece firmada por Gregorio Martínez Sierra, por lo que surgen mayores complicaciones a la hora de estudiarla, como es en este caso, desde la perspectiva de la que fue su mujer, María Lejárraga. Y es que, aunque este libro ve la luz únicamente firmado con el nombre de Gregorio Martínez Sierra, investigadores como Antonina Rodrigo (1992: 149) e Ian Gibson (1985: 269) confirman que la obra está escrita si no por completo, casi en su totalidad por Lejárraga. Muestra y prueba que apoya la teoría de estos investigadores es el uso de los mismos términos para describir Granada que la escritora utilizará 41 años más tarde en su libro, publicado en 1952 y ya afirmado bajo el nombre de María Martínez Sierra, Una mujer por caminos de España, donde evoca el primer viaje a la ciudad andaluza -del que surgió la obra que aquí se estudia- y donde le dedica amplios capítulos. Está amplia- 
mente estudiada la colaboración literaria que el matrimonio Martínez Sierra mantuvo durante medio siglo en el que la escritora renunció a firmar casi doscientas obras que aparecen con el nombre de su marido (Rodrigo, 1992; Blanco, 1999; O'Connor, 2003; Aguilera Sastre y Lizarraga Vizcarra, 2009). Esta colaboración literaria fue en los primeros años más equitativa, pero con el paso del tiempo hubo un progresivo distanciamiento tanto sentimental como laboral que desencadenó en que Lejárraga fuera la que se encargase, casi en exclusiva, de la creación literaria. Aun así, este estudio no pretende dejar de lado la influencia de Gregorio Martínez Sierra ya que esta obra surge de un viaje real que hicieron juntos y está escrita en los primeros años de matrimonio, por tanto, el empresario teatral, muy probablemente, le dictase sus impresiones y apuntes a Lejárraga.

\section{UNA MODERNISTA GUÍA EMOCIONAL}

Como se ha expuesto, esta obra surgió de un viaje real que hicieron los Martínez Sierra. La fecha exacta de la primera visita del matrimonio a Granada se podría datar en torno al año 1906 o 1907¹. Viajaron a Granada motivados por la primera salida al extranjero que realizaron por Europa en 1905, ya que en París, Bruselas, Londres y Berlín les preguntaban por las maravillas de las ciudades de Sevilla y Granada. Les pedían en diversos idiomas información sobre las posibilidades que podían ofrecer las dos ciudades andaluzas y ante esto, los dos viajeros confesaban con algo de vergüenza: «¿Sevilla? ¿Granada? No las conocemos» (Martínez Sierra, 1989: 121).

De este modo, fue la ávida curiosidad que percibieron claramente en su viaje por Europa hacia ambas ciudades andaluzas lo que llevó al matrimonio Martínez Sierra a viajar a Granada por primera vez. De aquella primera visita y de todas las demás que le sucedieron la escritora riojana destaca que fueron para ella «poesía pura» porque la ciudad de la Alhambra realiza dos prodigios en el alma de quien la visita: «exalta el individualismo e infunde la irresponsabilidad» (Martínez Sierra, 1989: 122). Con estas palabras Lejárraga planteaba que la estancia en Granada liberaba al visitante de todas sus cadenas y prisiones interiores, de todo lo que ata como los preceptos, reglas,

1 Lejárraga no recuerda exactamente la fecha pero ofrece como probable paréntesis temporal el que marcan estos dos años (Martínez Sierra, 1989: 121). 
doctrinas y filosofías, en definitiva; «todo lo que impide el libre vuelo del espíritu se desvanece por arte de hechicería» (Martínez Sierra, 1989: 122).

Así, esta obra, publicada por primera vez en 1911 en París, no se muestra como un libro de viajes ni tampoco como una guía de la ciudad al uso, sino que, como radica en su título, es una Guía emocional. Según el Diccionario de la lengua española de la RAE, guía aparece con la siguiente acepción: «Tratado en que se dan preceptos para encaminar o dirigir en cosas, ya espirituales o abstractas, ya puramente mecánicas» y emocional está descrito como relativo a la emoción, cuyo significado es: «Alteración del ánimo intensa y pasajera, agradable o penosa, que va acompañada de cierta conmoción somática». Así, este libro se presenta como un tratado que ofrece instrucciones y descripciones de las alteraciones del ánimo, en su mayoría agradables, que el viajero experimenta al descubrir por primera vez la ciudad granadina. Y es que la emoción está ligada la cultura, como bien explica Strongman en la siguiente síntesis sobre la psicología de las emociones:

Las relaciones entre las emociones y los productos culturales como la literatura, la música, el drama y el arte son muy significativas. Lo que se denomina comúnmente como arte depende de su impacto emocional: de hecho es difícil concebir los fenómenos artísticos sin su influencia en las emociones (Strongman, 1987: 229).

De este modo, se nos ofrece un itinerario por el impacto emocional que genera el arte y la cultura de la ciudad en la escritora. De hecho, en el prólogo de la obra, Lejárraga, adoptando el género y el papel de su marido, se dirige a las potenciales lectoras ${ }^{2}$ del libro para hablarles de la emoción que, aunque en numerosas ocasiones va ligada al dolor, es necesaria para la existencia humana, y, por tanto, la intención de esta obra es «haceros confidencia de mi propia emoción, para dar a la vuestra un punto de partida, para serviros de auxilio en la necesaria "composición de lugar" » (Martínez Sierra, 1920: 12). Pretende, por lo tanto, a partir de la descripción de las emociones que experimenta al visitar y vivir unos días en la ciudad, servir de guía a las lectoras y lectores de la obra. Así, este libro es una obra modernista, estilística y temáticamente, cargada de lirismo que utiliza la ciudad de Granada como pretexto

2 Esta obra está dirigida a «vosotras, mujeres que me leéis, hijas de España y de la América latina» (Martínez Sierra, 1920: 12) como muchas otras novelas, manuales de conducta, guías de todas clases y revistas que desde mediados del siglo XIX se dirigían fundamentalmente a mujeres (Valis, 2010: 296). 
modernista para alabar una topografía ideal del ensueño y la contemplación. Sin embargo, la obra no se limita en este aspecto, sino que, dentro de esas poéticas y emocionales descripciones de la ciudad, se inserta toda una serie de reflexiones sobre el papel de la mujer, el feminismo acuciante de esos años y la realidad política y social que estaba viviendo España.

\subsection{Topos de la ciudad muerta}

La obra es narrada por un viajero que relata en tercera persona sus emociones ante la ciudad. El viajero recorre Granada en compañía de una mujer y en algunos capítulos quien narra sus reflexiones y emociones es esta acompañante en primera persona. Asimismo, el libro está escrito en prosa poética por lo que se aleja, ya de entrada, del tono explicativo de una guía de viajes al uso. Así, para la lírica descripción de Granada, la obra va a fundamentarse en el topos de la ciudad muerta tomando algunas de sus características. Durante el siglo XIX se produjo una rápida mutación de las ciudades a consecuencia del acelerado progreso industrial apoyado por la burguesía y, a finales de este siglo, surgió una crisis de los valores del progreso y la modernidad que los escritores plasmaron en esta recreación de las ciudades muertas, ayudándose de valores ideológicos del simbolismo y del decadentismo, ya que este nuevo mundo industrial y su pragmatismo inherente, no solo dejaban fuera valores e ideales sino también ambientes y paisajes. De este modo, para estos escritores, la ciudad, en el proceso de modernización industrial, iba perdiendo su encanto íntimo y su identidad que provenía de la tradición (Lozano Marco, 2003: 20). Las denominadas ciudades muertas se caracterizaban por ser ciudades que disfrutaron de una gran época de esplendor histórico que se vio empañado por los avances de la modernidad y el progreso, pero, a pesar de esto, las urbes mantenían cierto aire melancólico que rememoraba ese esplendor pasado, «donde había desaparecido una vida en otro tiempo floreciente», eran lugares que se estaban adentrando en un presente moderno indigno de ellos, como en el caso concreto de monumentos y ruinas que estaban «cargadas de melancólicos recuerdos y embellecidas por el arte» (Hinterhäuser, 1980: 64).

En el caso de Granada. Guía emocional, Lejárraga va a tomar varias características de esta recreación literaria, de hecho se podría hablar de una influencia directa de Rodenbach -precursor de este topos con su obra Brujas 
la muerta (1892) - ya que desde el primer número de la revista Helios, revista modernista en la que participaba Gregorio Martínez Sierra, y por tanto, bajo el nombre de este, María Lejárraga, aparecen traducciones de poemas del escritor belga como el titulado "Campanas del domingo". Así, al igual que Rodenbach, el matrimonio Martínez Sierra escribe sobre una ciudad con un pasado lleno del esplendor, en este caso, de reyes árabes y cristianos, a los que alude con frecuencia en su discurso. Otra de las características que toma de este topos es que la ciudad muerta de la Guía emocional no es el lugar de residencia del escritor, sino que es la ciudad elegida para recrearla y transmitir un estado de ánimo y emociones; la ciudad elegida para confundirse con su melancolía. En definitiva y en palabras de Lozano Marco: «es un complejo símbolo poético que participa de una estética y de una geografía, pero donde lo que predomina es lo estrictamente poético» (2003: 18). En esta obra prima el elemento poético en las detalladas descripciones de los paisajes, las calles, barrios y monumentos, y las impresiones que causan los lugares en el visitante. Aunque este lirismo se encuentra latente en toda la obra, hay pasajes donde predomina un mayor despliegue de elementos poéticos como en los capítulos titulados "Elogio del amor de las fuentes y los arrayanes" y "El corazón que duerme bajo el agua", que describen los paisajes y la naturaleza granadina y de la Alhambra.

Sin embargo, también hay características que la obra no va a adoptar y a desarrollar tan en profundidad como se da en el topos de la ciudad muerta. Un ejemplo sería el profundo pesimismo que obras como Brujas la muerta toman del filósofo alemán Schopenhauer, y que, sin embargo, el libro de Granada. Guía emocional lo sustituye por una alegría burlesca, ya que la asociación entre Granada y el ocio era considerado como un ideal estético muy en consonancia con el que desarrolló Gustavo Adolfo Bécquer en "La Pereza" (Valis, 2010: 297). Esa alegría burlesca y la tendencia al ocio también están presentes en las primeras páginas del prólogo que dan la bienvenida a las lectoras: «Venid, pues, conmigo y veréis que maravillosamente nos vamos a perder, perdiendo el tiempo, bajo las polícromas arquitecturas y entre las frescas arboledas de la Alhambra» (Martínez Sierra, 1920: 14). No promete en el prólogo lógica, ni erudición, ni tampoco información minuciosa, pero lo que sí garantiza es locura, incoherencia, e irresponsabilidad de todas las emociones e impresiones que va a ofrecer de Granada. Como se puede comprobar, es una invitación al viaje y a la evasión, al disfrute y a la recreación de 
las emociones a través de la lectura de las páginas de este libro sin, a primera vista, esa saturación melancólica y decadente.

De este modo, en las descripciones poéticas de la ciudad que la escritora realiza, va a darle una gran importancia a la naturaleza que se funde con el monumento de la Alhambra, y entre cuyos elementos destaca de manera especial el agua. A lo largo de la Guía emocional se puede encontrar la presencia de este elemento dentro de las poéticas descripciones de la naturaleza que inunda la ciudad de Granada, una naturaleza irracionalizada en términos románticos y dotada de un halo espiritual y simbólico. Es muy revelador el especial hincapié que se hace al tratar el agua dentro de estas descripciones paisajísticas, ya que aquí sí se puede encontrar el elemento decadentista característico del topos de la ciudad muerta que enlaza con el recuerdo de la Granada árabe:

Así, el agua de la alberca, que debiera inquietarse con su lluvia, ha estado frente a mí siempre serena y quieta, cercada por su verde prisión de mirtos, como un espejo mágico, como una gran losa de lágrimas, cuajadas, por milagro de alquimia o de nigromancia, para cubrir dignamente el sepulcro en el que esté haciéndose polvo algún inmenso y atormentado corazón. Es una locura, ciertamente, una desatinada locura; pero es imposible mirar esta quietud de agua sin pensar que, bajo ella, se inquieta, en agonía interminable, algo que no puede vivir ni acabar de morirse. Los peces, como rojos puñales, van hendiendo aquel agua, que seguramente no es líquida; sus idas y venidas atormentan, como ideas informes que se agitasen en un cerebro fatigado, impidiendo en él, aun en la hora del sueño, la cristalización ansiada del reposo... (Martínez Sierra, 1920: 42).

Esta poetización del agua pertenece a uno de los capítulos que le dedica a la visita de la Alhambra, en concreto al Patio de los Arrayanes. El agua de la alberca, encerrada en la prisión que crea el jardín de los mirtos, es descrita como «un espejo mágico» capaz de reflejar el paisaje, en el que hay oculto un «corazón que duerme bajo el agua» que fue testigo de las antiguas historias de los afortunados que una vez habitaron allí. En la obra modernista, se da una concepción de la fuente como símbolo complejo pero una de sus vertientes es, precisamente, la de convertirse en espejo, así «la superficie laminada de la fuente ofrece al poeta la visión de un espejo» (Correa Ramón, 2006: 105). En este libro el agua está muy relacionada con el mundo árabe y orien- 
talista, no solo por los avances que estos desarrollaron, sino que, además, el agua funciona como una suerte de espejo, como un elemento evocador del esplendor de esa civilización; al mirar el agua que encierra la Alhambra el viajero es capaz evocar la imagen de «toda una procesión de jinetes moros cabalgando a la luz meridiana» o la otra imagen de «los ojos negros de alguna, quién sabe si mora o infanta prisionera de guerra o de amor en la torre, más centelleantes que ningún metal» (Martínez Sierra, 1920: 98).

\subsection{Crítica social y feminismo}

Granada. Guía emocional, además de hacer una lírica descripción e interpretación de la ciudad en términos modernistas, va a tener una importante carga de crítica social. Se encuentra, por tanto, a una María Lejárraga comprometida con su tiempo, que plasma en su obra la idea del combate contra una sociedad injusta. De este modo, la escritora no se limita a describir la ciudad y a dar datos sobre esta como se esperaría de una guía de viajes tradicional, sino que desarrolla un ensayo crítico sobre la sociedad española de principios de siglo XX.

Así, las alusiones a la sociedad, la civilización y el progreso van a extenderse por toda la obra. Ya en las primeras páginas del libro, entre las descripciones detalladas de cómo el viajero asciende hasta un hotel cercano a la Alhambra, en una noche sin luna y rodeado de las fragancias de lilas en flor y de sonidos de fuentes invisibles, la escritora inserta una crítica a la sociedad que califica de hipócrita y plagada de leyes cobardes:

Aquí el viajero, como que se aleja y aparta del mundo, como que cerradas las puertas de los sentidos a las sensaciones cotidianas, las abre a la visión elegida que ha de traerle el regalo de la emoción. [...] Aquí se dará el gozo de estar secreta y desatinadamente loco; aquí dirá a grandes voces interiores, que nadie sino él mismo ha de oír, los versos que no ha de escribir nunca; aquí se hará a sí mismo las más estupendas confesiones, y se reirá, mirándose al espejo, de la refinadísima hipocresía que representa la sonrisa cortés con que anda por el mundo, asintiendo a las palabras vanas, a los gestos convencionales, a las leyes cobardes y a las trabajosas mentiras de la grey humana, constituida en esa lamentable cosa que llamamos con el buen nombre de la sociedad (Martínez Sierra, 1920: 23). 
Critica a una sociedad donde las doctrinas e instituciones coartan la libertad del individuo. Granada, por tanto, representaría un oasis donde el viajero puede dejarse llevar por la irresponsabilidad y dar la espalda a esa sociedad que lo limita. Asimismo, la escritora también va a destacar en la obra hechos históricos concretos de su época:

El espíritu español no sufre cadenas; todas están saltando y rompiéndose por obra y gracia de este, una, cien, mil veces bendito individualismo... Y dejamos hacer, y hay una Monarquía, y un Gobierno que llaman conservador, y reglamentos pueriles, y fusilamientos absurdos... Y España calla, mientras Europa entera levanta por ella voces de protesta... (Martínez Sierra, 1920: 231).

Aquí la autora está haciendo alusión a los disturbios y violencia antigubernamental y anticlerical por parte de la clase obrera en la Semana Trágica de Barcelona, y según Nöel Valis (2010: 298), a la ejecución del maestro de escuela anarquista Ferrer en 1909, hechos que ocurrieron bajo el gobierno político conservador de Antonio Maura.

Lejárraga, entre el despliegue de emociones que la ciudad le despierta, también va a desarrollar reflexiones acerca de lo material y lo económico, y sobre cómo la influencia de ambos elementos llegan a pervertir no solo al ser humano, sino incluso a las religiones: «toda religión se pervierte en cuanto tiene un templo material, porque el sostener las piedras en pie cuesta dinero, y para lograrlo se vende el espíritu» (Martínez Sierra, 1920: 90). Afirma que la riqueza esclaviza y roba la humanidad, y establece que la idea de la propiedad es madre de toda injusticia y engendradora de toda sinrazón. Rechaza la concepción de felicidad como acumulación de riquezas comparándolo con la alegoría del carro de Platón, pero sin ninguno de los dos caballos y con un auriga totalmente ciego. Finalmente sentencia:

Duele el alma intensa y casi insoportablemente al pensar que esta poca riqueza que poseemos nos ha robado tanto de nuestra humanidad, más aún si se piensa que por lograrla hemos dado lo mejor de la vida; es decir, que compramos el derecho a la injusticia con nuestra propia mutilación (Martínez Sierra, 1920: 87).

A su vez, la escritora va a defender especialmente a las clases menos privilegiadas: a los obreros, los campesinos y los gitanos. Son muy significativos 
los capítulos que les dedica a los gitanos del barrio granadino del Albaicín, ya que rompen con la imagen tipificada de estos que solían buscar los turistas extranjeros. Describe algunas de sus costumbres, bailes como las zambras y también las cuevas donde muchos solían habitar ${ }^{3}$. Dentro de esa defensa que hace de los menos privilegiados, la escritora le va a prestar una mayor atención a la situación de la mujer. De hecho, se puede encontrar toda una defensa del feminismo esparcida a lo largo de la obra. Lejárraga era consciente de que en la sociedad de su tiempo la mujer estaba acostumbrada a escuchar la voz de la autoridad masculina, por lo que los razonamientos feministas en boca o letra de un hombre pesaban más que en las de una mujer, y, a su vez, al ser un hombre el que narraba, cómo en el caso de Granada. Guía emocional, se creaba una engañosa ilusión de imparcialidad con respecto al proyecto feminista. Así, al combinar una firma masculina y un narrador de este mismo sexo le permitía adoptar a la escritora un tono afirmativo y, en ocasiones, imperativo con su público femenino (Blanco, 1989: 27).

En los capítulos que dedica al pueblo gitano le concede un gran protagonismo a la figura de Lucía, una joven gitana alegre y vivaracha que solía hacer los espectáculos de bailes en las cuevas que visitó el matrimonio. En su paseo por el Albaicín, Lejárraga se percató de la Escuela del Ave-María fundada por Andrés Manjón, que gracias a su metodología pedagógica contribuyó a la educación del pueblo gitano que habitaba en el barrio. En estos capítulos, la escritora desarrolla todo un despliegue irónico para realizar una crítica al atraso de la España de principios de siglo XX con respecto a otros países europeos como Alemania «emporio de la ciencia y la industria» donde la civilización había llegado a un progreso mayor. Para realizar esta crítica sentencia la escritora:

Temo que, dentro de veinte años, los ojos negros de alguna gitanísima Lucía estén clavados sobre un libro de Nietzsche, y que sus lindos pies, en lugar de agitarse para la danza, se apresuren camino de un colegio electoral. Ya sabe leer, lo cual no es poco. Don Andrés Manjón tiene la culpa, Dios, por quien él lo hace, se lo perdone (Martínez Sierra, 1920: 172).

3 Hay que apuntar que, muy probablemente, la visita de Lejárraga a las cuevas y su contacto con el pueblo gitano en Granada inspirasen algunas de las partes de la obra que creó y estrenó con el músico Manuel de Falla en 1915: El amor brujo. 
Utiliza la ironía para denunciar el escaso número de alfabetización del pueblo gitano, especialmente en el caso de las mujeres. Asimismo, que cite al filósofo alemán no es coincidencia; Lejárraga era ampliamente conocedora de la obra de Nietzsche y, de hecho, la entrada del filósofo en el mundo intelectual y cultural de España fue el resultado de esa voluntad de europeización que llegó al país en torno a 1900 (Sobejano, 2004: 25). También resulta muy significativa la denuncia del hecho de que la mujer no pudiera votar; se debe tener en cuenta que este libro está escrito en la primera década del siglo XX y que hasta 1931 no fue reconocido en España el derecho al voto de las mujeres en la Constitución de este mismo año, y que fue en las elecciones generales de 1933 cuando las mujeres pudieron ejercer este derecho. Es más, fue la propia Lejárraga la que en las elecciones del 33 recorrió los caminos de España como militante del Partido Socialista Obrero Español pidiendo el voto femenino.

En otro de los capítulos de Granada. Guía emocional que la escritora dedica a la mujer, desarrolla toda una reflexión sobre el feminismo en España a partir de un diálogo entre dos jóvenes mujeres que se encontraban en la Alhambra, concretamente en el Mirador de Lindaraja; Maud y Carmela. Maud tiene veinticinco años, los ojos azules, ha nacido en Londres y ha aprendido español gracias a las lecturas que hace de textos en la lengua original de Santa Teresa; tiene una gran confianza, de hecho «cree en sí misma mucho más que en Dios» (Martínez Sierra, 1920: 72). Carmela tiene la misma edad que su compañera, los ojos casi negros y sabe latín, desconfía de su propia razón y «sonríe ante la seguridad con la que la inglesa afirma el pleno señorío de su voluntad sobre las contingencias de la vida interior» (Martínez Sierra, 1920: 72). La descripción de las dos mujeres que van a debatir sobre el feminismo no resulta caprichosa. Maud tiene confianza en sí misma y es inglesa; esto alude a los movimientos sufragistas femeninos del país anglosajón. Por el contrario, Carmela es más insegura y oriunda del pueblo español, donde la situación de la mujer en el ámbito público seguía siendo muy limitada; apenas podía acceder a este y solía depender de una figura masculina. Tampoco son casuales las alusiones a Santa Teresa, ya que representa la figura de una mujer escritora consagrada y porque, además, durante los años de entresiglos surge un nuevo interés sobre esta escritora del siglo XVI. Como explica Amelina Correa (2016: 127), los intelectuales de fin de siglo releen a esta mística en busca de esa plenitud espiritual, aunque intentando fusionar- 
la con sus particulares ideales artísticos, por lo que en este contexto, estética e ideológicamente muy complejo, se produce su recuperación desde otras perspectivas y desde otras necesidades vitales y espirituales.

El debate entre las dos jóvenes va a surgir precisamente del verso de la mística Santa Teresa de Jesús: «Vivo sin vivir en mí», ya que Carmela concibe esta frase como un acto de dependencia, es decir que «no hay vida que merezca nombre de tal, si no está fundida, deshecha, anegada, inefablemente perdida en otra...»y ante esto Maud va a afirmar que «España no es país de feministas» (Martínez Sierra, 1920: 73). Así comienza un debate que no solo enfrenta a dos mujeres con opiniones distintas sino que sería una suerte de dos pueblos, dos países, que están comparando la situación generalizada de la mujer que cada uno posee. Maud, la inglesa, opina que el renunciamiento no debe ser suprema obligación femenina, frente a Carmela que defiende que ese renunciamiento es una gran dicha y añade que la felicidad y el único sentido de la vida está en «cerrar los ojos y apoyar la cabeza en un pecho que creamos más fuerte que el nuestro, y escuchar la vida a través de la interpretación de una inteligencia muy amada» (Martínez Sierra, 1920: 75). Injusto y humillante son los adjetivos con los que Maud va a definir la explicación de la felicidad de Carmela. La española va a argumentar su respuesta haciendo un recorrido por algunas de las dificultades por las que debe pasar la mujer para estar al mismo nivel que el hombre en la sociedad, pero acaba resignándose con un «optimismo misericordioso». El diálogo final resulta muy interesante:

- ¿Quién te ha dado ese ramo de claveles?

- Le compré esta mañana frente a la Catedral ${ }^{4}$.

- Por eso le llevas en la mano. Yo llevo este único prendido en el pecho, porque me le ha dado alguien que me quiere... y esa es toda mi ambición feminista (Martínez Sierra, 1920: 75).

Muestra cómo la inglesa es capaz de obtener ella misma y de forma independiente un ramo de claveles, sin que tenga que regalárselo un hombre, por el contrario, Carmela alude a un ramo simbólico que sería metáfora del

4 Debe aludir con toda probabilidad a la costumbre durante mucho tiempo -hoy desaparecida- de las gitanas que vendían claveles en el entorno de la Catedral a los turistas y paseantes. 
amor. El personaje de Carmela se plantea como dependiente por partida doble; por un lado depende de la aprobación de una figura masculina y por otro lado depende de su relación amorosa, por lo que cualquier avance en el movimiento feminista es nulo ya que no tiene ninguna ambición por ello. Resultan muy reveladores este tipo de capítulos ya que reflejan nítidamente la conciencia política y feminista de María Lejárraga y, teniendo en cuenta que Granada. Guía emocional era una obra dirigida especialmente a las mujeres, es muy significativo que se hagan este tipo de planteamientos que, sin duda, harían reflexionar a las lectoras.

Y es que, Lejárraga desarrolló una intensa labor en el feminismo español; sus planteamientos feministas quedaban reflejados en las obras narrativas y dramáticas que el matrimonio publicaba, dictó conferencias, fundó asociaciones y participó activamente en el famoso Lyceum Club de Madrid (Alonso Valero, 2016: 81). De este modo, en Granada. Guía Emocional la escritora comienza a desarrollar conceptos que más adelante plasmará en los tres libros que condensan su teoría feminista: Cartas a las mujeres de España (1916), Feminismo, feminidad, españolismo (1917) y La mujer moderna (1920) (Aguilera Sastre y Lizarraga Vizcarra, 2009: 19).

Así, también se pueden encontrar en la Guía emocional reflexiones sobre los derechos y la situación de la mujer relacionada con personajes históricos que habitaron Granada. Lejárraga evoca entre los paisajes y monumentos de la ciudad a figuras históricas como Boabdil, Carlos V o los Reyes Católicos. En uno de los capítulos el viajero visita la Catedral en la que admira la obra de Diego de Siloé y la Inmaculada de Alonso Cano, y es durante la visita a la Capilla Real, frente a los sepulcros de los Reyes Católicos, donde Lejárraga evoca a la Reina Isabel e inserta con una gran sutileza reflexiones sobre la mujer y el heroísmo. Ya en un capítulo que se situaba en el Mirador de la Reina y en el que recordaba a Carlos V y a la Emperatriz Isabel, la escritora, había reflexionado sobre el concepto de mujer del héroe, en el que establecía la figura del héroe como uno de los seres más dañinos e insoportables. Explica que estos, en primer lugar no saben más que hablar de sí mismos y contar sus hazañas y aspiraciones, y advierte irónicamente a las lectoras de enamorarse de este tipo de hombres. Afirma que el héroe casi nunca se encuentra en su hogar y el problema radica en que ese tiempo no lo invierte en otras actividades provechosas o lúdicas sino que lo pasa batallando. Mientras el héroe lucha, vive aventuras y alcanza la gloria, su mujer espera paciente y 
fiel. Mientras él disfruta de una vida llena de triunfos, ella se preocupa: «La esposa se desvela, y el héroe ronca» (Martínez Sierra, 1920: 64). Estamos asistiendo a una crítica hacia esa división en la que la sociedad establece dos ámbitos: el ámbito público, esencialmente masculino, y el ámbito privado al que queda relegada la mujer, pero no solo eso, con estas palabras está aludiendo a toda la tradición literaria que tiene como protagonistas a este tipo de héroes, y al culto del héroe que, como afirma Gullón (1990: 67), el modernista había heredado y adaptado del romanticismo. La crítica se hace de manera muy fina, con ironía, hilando con todas las descripciones y evocaciones de Granada, y dirigiéndose de manera directa a las lectoras. A su vez añade que, a diferencia del caso de los héroes, es muy difícil serles a ellos, aunque sea, levemente infiel: «La esposa está moralmente obligada a sentirse la mujer más feliz de la tierra, y cada triunfo de él es como un eslabón que la ata más y más inexorablemente al carro de su triunfo» (Martínez Sierra, 1920: 66). Así, frente al sepulcro de la Reina Isabel, la recuerda y engrandece su figura desarrollando la idea del heroísmo femenino, este cargado de connotaciones positivas. A pesar de que Lejárraga confiesa que le pareció una mala idea la decisión de la Reina de la expulsión del mundo árabe de Granada, sí le reconoce su valentía de, como mujer, ponerse al mando de situaciones en las que siempre habían estado hombres. De hecho, la compara con Teresa de Jesús, a la que Lejárraga también admiraba, y establece la idea de algo que tenían las dos mujeres en común: «Sutilizan en la acción hasta la quinta esencia de las responsabilidades; sin vanidad de su grandeza, porque la pesadumbre de las ideas seculares hacen creerse intrusas a estas mujeres admirables en los reinos del heroísmo» (Martínez Sierra, 1920: 186), reinos siempre ocupados y dirigidos por hombres.

\section{CONCLUSIÓN}

Tras el recorrido por las calles y paisajes de Granada, por la sociedad española de principios de siglo XX y por la situación que la mujer vivía en esta; es al final del libro cuando la obra se comporta como una guía tradicional propiamente dicha y, brevemente, recomienda e indica hospedajes, restaurantes, casas de baños, telégrafos, bancos, etc. Y es donde la escritora aconseja la ciudad de Granada a «las personas que hayan adquirido el vicio espiritual de sufrir sus penas con rebeldía; a las que estén tocadas de melancolía, al pa- 
recer incurable, por abusos de auto-análisis y prolijos exámenes de conciencia» (Martínez Sierra, 1920: 236). Con estas palabras, Lejárraga constituye a Granada como un oasis restaurador donde huir de la vida cotidiana y donde sanar el espíritu.

Así y a modo de conclusión, Granada. Guía emocional se presenta como una obra muy amplia y fecunda en cuanto a los temas que desarrolla y se aleja tanto del concepto tradicional como de la idea preconcebida de una guía de viajes al uso, ya que además de hacer unas líricas descripciones de la ciudad de Granada, inserta entre la poética narración toda una serie de reflexiones sobre la sociedad del momento y sobre el papel de la mujer. Así, esta obra se erige como un tratado de las emociones que se experimentan en Granada y, a su vez, un ensayo crítico sobre la sociedad de principios de siglo XX.

\section{REFERENCIAS BIBLIOGRÁFICAS}

Aguilera Sastre, Juan y Lizarraga Vizcarra, Isabel (2009), «Introducción» a María Martínez Sierra Tragedia de la perra vida y otras diversiones. Teatro del exilio, 1939-1974, Madrid, Editorial Renacimiento, Biblioteca del Exilio.

Alonso Valero, Encarna (2016), Machismo y vanguardia. Escritoras y artistas de la España de preguerra, Madrid, Devenir.

Blanco, Alda (1989), «Introducción» a María Martínez Sierra Una mujer por caminos de España, Madrid, Castalia.

- (1999), María Martínez Sierra (1874-1974), Madrid, Ediciones del Orto.

CORREA RAMÓN, Amelina (2006), «Antonio Machado en el ámbito del modernismo andaluz», en Jordi Doménech (Coord.), Hoy es siempre todavía. Curso Internacional sobre Antonio Machado, Sevilla, Renacimiento, págs. 87-138.

- (2016), «Nada te turbe, nada te espante: tres lecturas disidentes de Teresa de Jesús en el fin de siglo hispano», en eHumanista, 32, págs. 126-148.

EISENBERG, Daniel (1995), «Una temprana guía gay: Granada (Guía emocional) de Gregorio Martínez Sierra (1911)», en Luce López-Baralt y Francisco Márquez Villanueva (Eds.), Erotismo en las letras hispánicas. Aspectos, modos y fronteras, México, Centro de Estudios Lingüísticos y Literarios, Publicaciones de la Nueva revista de filología hispánica, págs. 111-120. 
Gibson, Ian (1985), Federico García Lorca. 1. De Fuente Vaqueros a Nueva York (1898-1929), Barcelona, Grijalbo.

Gullón, Ricardo (1990), Direcciones del modernismo, Madrid, Alianza Editorial.

HinterhäUser, Hans (1980), Fin de siglo. Figuras y mitos, Madrid, Taurus Ediciones.

Lozano Marco, Miguel Ángel (2003), Imágenes del pesimismo. Literatura y Arte en España 1898-1930, Alicante, Universidad de Alicante.

Martínez Sierra, Gregorio (1920), Granada. Guía emocional. Madrid, Estrella.

Martínez Sierra, María (1989), Una mujer por caminos de España, Madrid, Castalia.

O'ConNoR, Patricia W. (2002), «Sortilegio de amor y los trágicos triángulos en la vida y obra de María Martínez Sierra», en Juan Aguilera Sastre (Coord.), María Martínez Sierra y la República: Ilusión y compromiso: II Jornadas sobre María Lejárraga, Logroño, Instituto de Estudios Riojanos, págs. 15-34.

- (2003), Mito y realidad de una dramaturga española: María Martínez Sierra, Logroño, Instituto de Estudios Riojanos.

Real Academia Española (2014), Diccionario de la lengua española (23. a ed.). Consultado en http://www.rae.es/ [10 de noviembre de 2017].

Rodenbach, Georges (2011), Brujas, la muerta, Madrid, Vaso Roto.

Rodrigo, Antonina (1992), María Lejárraga, una mujer en la sombra, Barcelona, Círculo de Lectores.

Sobejano, Gonzalo (2004), Nietzsche en España, 1890-1970, Madrid, Editorial Gredos.

Strongman, Ken T. (1978) The psychology of emotion, New York, John Wiley \& Sons.

VALIs, Nöel (2010), La cultura de la cursilería. Mal gusto, clase y kitsch en la España moderna, Madrid, A. Machado Libros. 